\title{
Comment on Hobbs and Kerr: Will consumers lose or gain from the environmental impacts of transgenic crops?
}

\author{
Sara Scatasta
}

Hobbs and Kerr (2004) highlight three key issues to be taken into consideration when analysing the impact of genetically modified (GM) food on consumer welfare. The first issue is the direct impact that GM food will have on consumers through consumption activities in terms of market price and quantities. Assuming GM crops are associated to lower production costs and higher yields, these advantages could be passed on to the consumer in terms of lower market price and higher marketed quantities. The second issue is the indirect impact that GM will have on consumers through changes in quality attributes of related food products as perceived by the consumer. Potential environmental and health impacts related to the consumption of GM food and single consumers' perceptions of these impacts may lead some consumers to be against GM foods. The third issue highlighted by Hobbs and Kerr is the impact of introduction or absence of mandatory GM and voluntary non-GM labelling (here referred to as GM labelling).

On the one hand, since consumer preferences have already been altered by media coverage of topics related to GM food, and since GM is a credence attribute, the introduction of GM labelling may have a positive effect on welfare for consumers who prefer not to consume genetically modified (GM) food. At the same time GM labelling may impose additional costs to producers of GM or non-GM depending on how GM labelling is implemented. For example, in the case of voluntary non-GM labelling, non-GM producers will incur higher costs of demonstrating that their products are non-GM. This may result in higher market prices of non-GM products. On the other hand, absence of GM labelling would result in lower market prices but have a negative effect on welfare for those consumers who do not want to consume GM food.

Several studies have been carried out to investigate the impact of eco-labels on consumption behaviour with respect to environmentally friendly goods (see, for example, Nimon and Beghin 1999; and Wessells, Johnston and Donath 1999). The conclusion was that the consumer might be willing to pay a premium for products that are perceived to be more environmentally friendly than others. Thus, consumers who associate GM food with environmental damages might be willing to pay a premium to avoid consuming those products. If the introduction of GM labelling does not raise the price of non-GM products above this premium, then GM labelling should be introduced. The paper by Hobbs and Kerr supports this conclusion, noting that another important factor in establishing the impact of GM labelling on consumer welfare is consumer expectation about the rate of adoption of GM crops by food

\footnotetext{
\# Environmental Economics and Natural Resources Group, Wageningen University, Hollandseweg 1, 6708 KN Wageningen, the Netherlands. E-mail: sara.scatasta@wur.nl
} 
producers. The loss in consumer welfare will be directly related to the rate of adoption of GM crops.

In concluding, it should be noted that there is an additional factor that needs to be taken into consideration when analysing the impact of GM labelling on consumer welfare: being non-GM may not be the only attribute differentiating two food products. Other attributes such as taste and colour may be of interest to the consumer regardless of the preference for GM foods. An increase in product price due to the introduction of GM labelling makes all other product attributes more expensive to the consumer. Thus, GM labelling may have a negative impact on welfare for those consumers who do not care about consuming non-GM food if they have strong preferences for some other attributes of non-GM products. In this context it becomes essential to study the impact of GM labelling on consumer welfare on a case-by-case basis.

\section{References}

Nimon, W. and Beghin, J., 1999. Are eco-labels valuable? Evidence from the apparel industry. American Journal of Agricultural Economics, 81 (4), 801-811.

Wessells, C.R., Johnston, R.J. and Donath, H., 1999. Assessing consumer preferences for ecolabeled seafood: the influence of species, certifier, and household attributes. American Journal of Agricultural Economics, 81 (5), 1084-1089. 